\title{
PROPOSED ON BOTTOM STABILITY DESIGN PROCEDURE FOR SUB SEA PIPELINES CONSIDERING PIPELINE OSCILLATIONS
}

\author{
Mostafa Zidan, Mohamed Abd ElMotaal, A. M. Azouz \\ Ain Shams University, Egypt
}

\begin{abstract}
This paper describes a proposed procedure to calculate the stability, against lateral movement, of submarine pipelines resting on the seabed and exposed to wave or combined wave and current loadings. The procedure provides an estimate of the expected pipe embedment created by wave induced oscillatory pipe motions. Based on this expected pipe embedment into the soil, realistic hydrodynamic and soil force formulations ${ }^{1,2}$ are used to check pipe stability for loadings expected during the design event.
\end{abstract}

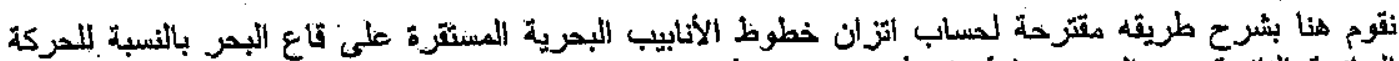

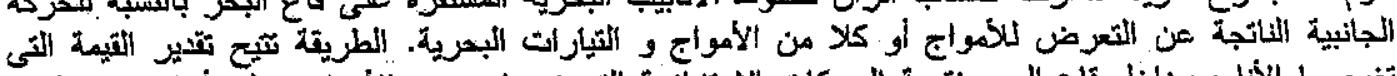

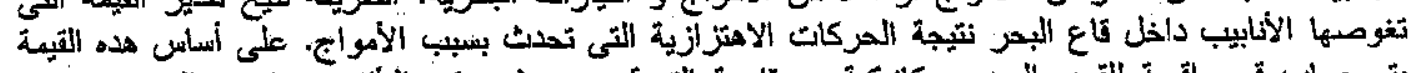

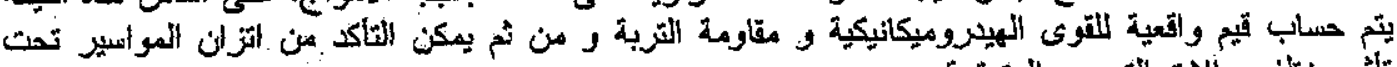

$$
\begin{aligned}
& \text { تأثيرمختلف حألات الثصميم المثتو لأعينة. }
\end{aligned}
$$

Keywords: Proposed On bottom Stability Design, Pipe Soil Interaction Model.

\section{INTRODUCTYON}

During the last decade, the Pipeline Research Council of the American Gas Association has sponsored a coordinated research effort into the underlying forces associated with the on-bottom stability of offshore pipelines ${ }^{3}$. This research included large scale model tests designed to investigate both hydrodynamic forces and the pipe/soil interaction process. This researches ${ }^{3}$, as well as research by others $s^{4}, 5$, have indicated that traditional on-bottom stability analysis techniques are not accurate in oscillatory flow conditions. Inaccuracies in the traditional method include both hydrodynamic and pipe/soil interaction forces.

Traditional stability analyses have typically utilized a Morison type hydrodynamic force formulation, and force coefficients selected have been on the order of $1 / 2$ to $1 / 4$ of those required to accurately predict the peak hydrodynamic drag and lift forces in oscillatory flow. In addition, the Morison type force formulation poorly represents the temporal variation of the hydrodynamic lift and drag forces for pipelines resting on the seabed and subjected to combined wave and current loads ${ }^{1,6}$.

Traditional stability analysis techniques have also typically utilized a frictional type soil resistance. New research indicates that soil resistance should be modeled using both a frictional term as well as a "remaining" term which is independent of the normal load between the pipe and soil 287 . This later term may be quite large, especially for weak marine sediments where large pipe embedments are experienced.

Because of these problems with traditional analysis methods, large scale model tests were planned and the results have been used to develop accurate methods of calculating; a) hydrodynamic forces in oscillatory flow conditions, and b) lateral soil resistance forces ${ }^{2}$. These results have been implemented into a pipe dynamics simulation tool ${ }^{8}$.

With the pipe dynamics tool it is possible to perform a detailed simulation of a pipe response to waves and current. However, the dynamic simulation is not ideal for design use because the simulations are time consuming, and results do not give direct information regarding weight coating requirements. This cumbersome nature prompted development of the proposed analysis technique described in this paper. The method was developed based on a rational engineering analysis of the problem. First, a static analysis is sufficient for cases where net pipe movements will not be allowed. Second, the pipe/soil interaction tests ${ }^{287}$ indicated that, small pipe oscillatory movements can cause great increase in pipe embedment and consideration of this embedment is necessary in order to accurately 
describe the soil resistance. Thus, the proposed analysis includes.

1. Accurate representation of hydrodynamic forces (both magnitude and temporal variation) based on a Fourier model developed from large scale model tests'

2. pipe/soil interaction model which includes not only a two component lateral resistance, but also simulates the process of pipe embedment due to small oscillatory motions caused by wave and current loadings.

A sea state model which characterizes bottom hydrodynamics from spectral representation rather than a single regular wave (as is typically the case in traditional design) ${ }^{9}$.

\section{ASSUMPTIONS}

The hydrodynamic forces are based on near seabed velocities from a wave spectrum transformed to a bottom velocity spectrum. The soil resistance is based on a pipe/soil model which includes pipe movement history effects ${ }^{2}$, and an assumed loading history. The loading history corresponds to build-up of the design sea state. The number and magnitude of force oscillations are based on the statistical distribution of wave heights in a rapidly developing sea state. This gives the smallest number of large waves, and thus conservatively estimates embedment. The resulting pipe embedment and soil resistance values are used to check pipe stability.

The wave forces are calculated based on wave induced velocity amplitudes, and use the Fourier force formulation described by Jacobsen et. al. ${ }^{1}$. The basic assumptions for the proposed design procedure of analysis are as follows:

1. Small pipe movements during an assumed storm build-up just prior to the design storm are allowed to embed the pipe.

2. For the stability check, the pipe is assumed stationary and resting on the seabed.

3. Only a point on the pipeline is considered in the analysis and this point is assumed to act independent of adjacent pipe. That is; the effect of pipe stiffness is not included in the analysis.

4. Wave induced near sea bed water particle velocities are assumed to have a Rayleigh distribution (i.e. similar to the wave height distribution).

5. Bottom velocity amplitudes are based on a 3-hour storm duration with input sea state spectral parameters.

6. Soil resistance is based on the new pipe/soil interaction model $^{2}$ which includes a frictional resistance (dependent on the pipe normal force applied to the soil) and a "remaining" resistance (dependent upon pipe embedment and independent of instantaneous pipe normal force).

Pipe embedment is developed by a pipe movement history (determined in the fashion described in Steps
2 through 4 of the Calculation Procedure below) and is computed using conservative assumptions which include the following:

1. No pipe embedment is considered to have occurred until just prior to the design storm.

2. A short, 4-hour storm build-up period is assumed to precede the design storm during which some pipe embedment is allowed to occur. The significant wave height during the build-up period is assumed to start at zero and increase linearly with time to the significant wave height of the design storm (see Figure 1).

3. The pipe is considered to undergo only very small oscillations (less than 0.07 pipe diameters).

4. Pipe embedment at the end of the storm build-up period is based on 200 small amplitude cyclic oscillations. The amplitude of the oscillations is limited by the lesser of; a) assumption (3) above, or b) that which the hydrodynamic forces expected from a rapidly developing build-up sea state can produce.

5. Subsequent pipe embedment during the design storm is estimated using 50 small amplitude cyclic oscillations of the pipe. The amplitude of these oscillations is also limited by assumption (3) above or that which the hydrodynamic forces contained in the design storm can produce.

With these assumptions, the proposed design procedure provides a better estimate of pipe embedment than static calculations which do not consider the effect of pipe movement. Figure 5 shows the logic for determining pipe embedment.

\section{PROPOSED CALCULATION PROCEDURE}

Very briefly, the procedure includes calculation of the bottom velocity spectrum from which statistically meaningful bottom velocity amplitudes are determined and used with the input current to calculate hydrodynamic forces. Pipe embedment is next calculated using a quasi-static simulation of pipe oscillations generated by the largest wave loadings occurring in the storm build-up period. Static pipe stability is next checked using these calcuiated forces and reported as a safety factor (available soil resistance versus hydrodynamic loading).

Further, some of the additional embedment which may be expected during the design event is calculated. Based on the total pipe embedment (after build-up plus some occurring during the actual storm), soil and hydrodynamic forces are recalculated and stability checked. Thus, the procedure provides information about the stability to be expected at the beginning of the design event as well as the potential for additional stabilization during the design event.

A step-by-step discussion of the procedure follows.

1. The wave height spectral density function is calculated and then transformed to a bottom 
velocity spectral denisity function. From this. The significant bottom velocity and zèro crossing periods (on bóttom) are calculated.

2. Maximum and minimum in-line hydrodynamic forces for the largest 400 wave loadings contained in an assumed 4-hour long build-up sea state are calculated. The assumed 4-hour long build-up period is considered to start with a significant wave height equal to zero and linearly increase with time to that of the design sea state, see Figure 1. The on-bottom zero crossing period is assumed to remain constant and equal to the ont-bottom zero crossing period of the design sea state. The 400 largest waves are approximated by the five wave induced velocity amplitudes illustrated in Figure 2.

Hydrodynamic forces for each of these velocity amplitudes are calculated using the new hydrodynamic force calculation procedure and the associated data base of force coefficients described by Jacobsen et.al. ${ }^{1}$. The calculation assumes a regular wave, and forces are calculated for each degree of the entire 360 degrees of wave passage.

3. Maximum and minimum in-line forces for the largest 100 wave loadings during a subsequent 3-hour long design sea state are calculated similarly to Step 2 above. These 100 wave loadings are described by the four wave induced velocity amplitudes illustrated in Figure 3.

4. Based on the forces calculated in Step 2, an estimate of pipe embedment at the end of the 4hour storm build-up period is calculated. This estimate is obtained by subjecting the pipe to 200 small oscillations. The oscillations are limited in amplitude to be no larger than that which the wave forces (calculated in Step 2) can produce, or 0.07 times the pipe diameter, whichever is smaller. The number of large wave forces which can be applied to cause embedment is limited to half the number of the wave loadings for each velocity amplitude characterized in Figure 2. To simulate the buildup sea state, the smaller waves shown on Figure 2 are considered first Not all of the 200 oscillations necessarily produce pipe embedment. Only those which generate in-line forces sufficient to overcome frictional resistance between the pipe and soil are considered to produce embedment ${ }^{2}$.

For each of the 200 wave loadings, the in-line hydrodynamic force is reduced to account for the pipe embedment just prior to its application. The estimated pipe embedment and the available soil resistance force at the end of the build up period is then saved for further processing. Pipe embedment and history dependent soil resistance are calculated using the new pipe/soil interaction model ${ }^{2}$.
5. Based on the forces calculated in Step 3 and the pipe embedment calculated in Step 4, the amount of additional pipe embedment that can be produced by half of the largest 100 waves in the design sea state (i.e., 50 more oscillations), is calculated in a fashion similar to that described in Step 4 for the storm build-up period. This embedment and the associated soil resistance force is saved for further processing.

6. Hydrodynamic forces for a complete wave cycle are calculated for four statistical bottom velocity amplitudes in the 3-hour long design sea state. The four bottom velocities are:

$$
\begin{aligned}
& U_{1 / 3}=1.00 \mathrm{Us} \\
& U_{1 / 10}=1.27 \mathrm{Us} \\
& U_{1 / 100}=1.66 \mathrm{Us} \\
& U_{1 / 000}=1.86 \mathrm{Us}
\end{aligned}
$$

These hydrodynamic forces are calculated using the new force formulation', and include reductions due to the pipe embedment into the soil (calculated in Steps 4 and 5).

7. Using the soil resistance values obtained in Steps 4 and 5 and the hydrodynamic forces calculated in Step 6 , the minimum safety factor against lateral sliding is calculated for the pipe embedment at the end of the 4-hour long build-up period, and at the end of the 3-hour long design sea state.

The safety factor is calculated from:

$$
\text { Safety Factor }=\mu\left(W_{s}-F_{L}(t)\right)+F_{H} /\left(F_{0}(t)+F_{1}(t)\right)
$$

And the minimum safety factor reported during passage of each wave.

The above procedure was adopted after the results of dynamic analyses were used to calibrate and confirm that the results for pipe embedment are reasonable and that the results are conservative. Figures 4 and 5 illustrate this procedure graphically.

\section{VERIIICATION/ CALIBRATION OF THE PROCEOURE}

During development of the proposed design procedure, numerous dynamic analyses were performed to verify and calibrate the embedment calculation. A summary of one series of analyses is tabulated in Table 1; it compares the embedments predicted by the simplified design procedure with those obtained from a 4-hour dynamic analysis of the storm build-up period.

For the dynamic simulation, a 4-hour hydrodynamic force time series was generated using the software described by Lammert et. al. ${ }^{8}$. Then the simulation was performed using the dynamic simulation program, and scaling the hydrodynamic forces for each 20-minute segment of the simulation. See Figure 6. Drag and lift forces were scaled by the wave height ratio squared, and the inertial force was scaled by the wave height ratio. 
The comparison shows that the simplified method fairly accurately predicts the pipe embedments calculated in the dynamic analyses. In addition, the embedments calculated by the simplified method are conservative (underpredicted) in all but one case. For this case, the prediction was within $5 \%$ of the value calculated in the dynamic analysis.

\section{STABILITY CRITERIA}

As previously discussed, the check for pipeline stability is a safety factor (Eq. 1) which compares available soil resisting forces to the hydrodynamic loads. For each concrete coating thickness, the stability check is done for four statistical loadings. The four hydrodynamic loadings are those associated with $U_{1 / 3}, U_{1 / 10}, U_{1 / 100}$, and $U_{1 / 1000}$ bottom velocities (i.e. the average of the highest $1 / 3,1 / 10,1 / 100$, and $1 / 1000$ wave induced bottom velocity amplitudes, respectively).

This stability check is also done for two different embedment predictions. First, embedment is calculated based on an estimate of the wave load content during a short, 4-hour storm build-up period. Then, additional embedment which could occur during a 3-hour design storm (if the pipe does not break-out of the soil) is estimated, and stability is checked based on that embedment.

The first set of safety factors for Us to $U_{1 / 1000^{\prime}}$ provides information regarding pipe stability at the end of the build-up period. If stable in $U_{1 / 1000}$ (maximum wave loading), the pipe is very stable because the probability of having a wave larger than $\mathrm{U}_{1 / 1000}$ is very small. Essentially no wave in the design storm can cause the pipe to break-out of the soil.

If at the end of the storm build-up, the factor-ofsafety is less than 1.0 for $U_{1 / 1000}$ ' but is greater than 1.0 for $\mathrm{U}_{1 / 100}$; the pipe has a high probability of becoming stable for $U_{1 / 1000}$ during the early stages of the 3-hour storm. If the pipe is stable in the $U_{1 / 100}$ condition, then there are less than 5 waves in a 3hour design storm which can generate forces large enough to cause a "break-out" of the pipe. Thus, the possibility of further embedment before seeing $U_{1 / 1000}$ in the design storm is very good, and the pipe would have a very good chance of becoming stable in the design storm.

This is what the second set of safety factors (including some embedment from the 3-hour storm) are intended to identify. They indicate whether or not the pipe has the potential to become stable in the design storm. A safety factor greater than 1.0 for $\mathrm{U}_{1 / 1000}$ after additional embedment from the design storm indicates that the pipe has the potential to become stable during the design event.

Based on comparisons with fully dynamic analyses, using the following criteria will produce pipes which do not move significantly (less than the pipe diameter) when analyzed with the dynamic softwares.

1. At the end of storm build-up, the pipeline should be stable in the $U_{1 / 100}$ condition, and

2. During the 3-hour storm period, the pipeline should become stable in the $U_{1 / 1000}$ condition.

Table 2 shows results from a typical analysis. This table gives the calculated embedments and safety factors for $U_{1 / 100}$ and $U_{1 / 1000}$. Also illustrated is the concrete thickness selected based on the above stability criteria.

Requirements for vertical stability (hydrodynamic lift versus pipe submerged weight) have not been well defined in the past. With traditional design methods, where lift forces were underpredicted and only frictional soil resistance was considered, it was generally accepted that vertical stability should be satisfied. That is, the hydrodynamic lift force should not exceed the submerged weight of the pipe. Because the only restraining force was soil friction (dependent on pipe normal force) vertical stability was always satisfied in order to produce a lateral resistance. However, with the new soil models ${ }^{287}$, which incorporate both a frictional term and a remaining term (not dependent upon pipe normal force), lateral stability can be satisfied without satisfying vertical stability. With many designs, it is now anticipated that the hydrodynamic lift force for the largest waves will exceed the pipe weight. This is not believed to be a problem, but the issue of vertical stability needs to be addressed further, and consideration given to the facts that:

1. Passive soil resistance will tend to restrain lateral pipe movement even when the net normal pipe load is zero;

2. Lift force reduces drastically if there is any flow under the pipe. (e.g., if the pipe starts to lift off of the soil, or in permeable soils); and,

3. Cohesive soils can produce a suction force on the pipe to restrain it from vertical motion 10 .

\section{CONCLUSION}

The most significant result coming from the proposed design procedure is the dependence of pipeline stability on bottom sediment strength. In general, the results show that less concrete coating is required in soft marine soils (clays with remolded undrained shear strength less than 40 to $60 \mathrm{psf}$ and sands with relative density less that 40 to $60 \%$ ) than traditional pipe designs. This also points to the need for more accurate assessment of soil strength at the soil surface.

The applicability of the simplified or dynamic analysis techniques ${ }^{8}$ during the design process depends primarily on the nature of the bottom soil conditions, the type of information required from the analysis, and allowable pipe movements. In general, the design process is most efficient if the simplified 
analysis is used to check the effect of numerous weight coatings. These results can then be used to guide the dynamic analysis if necessary.

A dynamic analysis will not typically be required in the weaker of typical marine sediments. In clays, dynamic analysis will not necessarily be of interest if the simplified analysis indicates the pipe to be stable and the undrained shear strength of the seabed soil is less than about $100 \mathrm{psf}$. In sands, the same is true for a relative density less than about $60 \%$ to $70 \%$. The dynamic analysis will show that the pipe either embeds or does not move, or it undergoes large movements

In dense sands or stiff clays, a pipe will not embed a great deal regardless of its submerged weight. For these soils large pipe weights are required to assure no pipe movement, and allowing some movement may be desirable. For these cases, dynamic analysis can be used to predict the degree of pipe movement and the level of bending stress induced into the pipe by the movement.

To summarize, pipes designed to be stable using the simplified design approach will not move significantly (more than one times the diameter) during a fully dynamic analysis. Pipes which the simplified analysis indicates are unistable may move significantly during a dynamic analysis. This is especially true for soft clays and loose sands where much of the soil resistance stems from the pipe embedment into the soil during the storm build-up. If movements cause the pipe to break-out the large loss of soil resistance then makes the pipe very unstable and large movements can be expected. Thus, pipes in soft clays and loose sands should be designed to be stable using the simplified method; however, pipes in stiff clays or dense sands may be designed with either the simplified method (no net movements) or with dynamic analysis (allowing some pipe movement).

\section{REFERENCES}

[1] Jacobsen, V. , Bryndum, M. B., and Bonde, C. L. : "Fluid Loads on Pipelines - Sheltered or Sliding," 2.1st Offshore Technology Conference, OTC No. 6056, Houston, 1989 .

[2] Brennodden I H.; Sotberg, T., Leing) J.; and Verley R.: "An Energy Based Pipe-Soil Interaction Model," Proc. of the 21st Offshore Technology Conference, Paper No. 6057, Houston, 1989.

[3] Allen, D.W., Hale, J.R., Jacobsen, V. and Lammert, W.F.: "Submarine Pipeline OnBottom Stability: Recent AGA Research," 21st Offshore Technology Conference, OTC No. 6055, Houston, 1989.

[4] Wolfram, W.R.Jr., Getz, J.R, and Verley, R.L.P.: "PIPESTAB: Improved Design Basis for Submarine Pipeline Stability," 19th Offshore
Technology Conference, Paper NO.5501, Houston, 1987.

[5] Palmer, A.C., Steenfelt, J.S., Steensen-Bach, J.O., and Jacobsen, V.: "Lateral Resistance of Marine Pipelines on Sand," 20th Offshore Technology Conference, OTC No. 5853, Houston, 1988.

[6] Lambrakos, K.F., Chao, J.C., Beckman, H., and Brannon, H.R.: "Wake Model of Hydrodynamic Forces on Pipelines," Ocean Engineering, Vol. 14, No. 2, pp. 117-136, 1987.

[7] Wagner, D.A., Murff, J.D., Brennodden, H., and Sueggen, 0.: "Pipe-soil Interaction Model," 19th Offshore technology Conference, OTC No. 5504, Houston, 1987.

[8] Lammert, W.F., Hale, J.R., and Jacobsen V.: "Dynamic Response of Submarine Pipelines Exposed to Combined Wave and Current Action," 21st Offshore Technology Conference, Paper No. 6058 , Houston, 1989.

[9] Borgman, L.E., and Hudspeth, R.: "The Effect of Random Seas on Pipeline Stability - Volumes I \& I", a Pipeline Research Publication of the American Gas Association, Arlington, VA, 1984.

[10]Karal, K.: "Time Effect on the Lateral Soil Resistance to Pipeline Movement," Second International Offshore Mechanics and Arctic Engineering Symposium, Houston, Texas, pp. 504-509, 1983.

\section{NOMENCLATURE}

$\mathrm{U}_{1 / 3} \mathrm{U}_{\mathrm{s}}$ average of the largest one-third near seabed wave induced velocity amplitudes

$U_{1110}$ average of the largest one-tenth near seabed wave induced velocity amplitudes

$U_{1 / 100}$ average of the largest one-hundredth near seabed wave induced velocity amplitudes

$U_{1 / 1000}$ average of the largest one-thousandth nearseabed wave induced velocity amplitudes

$U_{C} \quad$ bottom current velocity

$W_{s}$ submerged weight of the pipe

$\mu \quad$ coefficient of soil friction

$F_{H}$ lateral soil resistance from lateral earth pressure (including embedment from pipe movement-history)

$F_{L}(t)$ hydrodynamic lift force as a function of time

$F_{0}(t)$ hydrodynamic drag force as a function of time

$F_{1}(t)$ hydrodynamic inertial force as a function of time

$\mathrm{H}_{S} \ldots$ significant wave height

$T_{p}$. peak period

$\mathrm{T}_{2}$ zero crossing period

$S_{u}$ Undrained shear strength

D, Relative density 
Table (1) Comparison of Embedments Calculated in the Proposed Method with Those Obtained Using a Fully Dynamic Simulation

\begin{tabular}{|c|c|c|c|c|c|c|c|}
\hline \multirow{2}{*}{$\begin{array}{c}\text { Water } \\
\text { Depth } \\
\text { (Ft) }\end{array}$} & \multirow{2}{*}{$\begin{array}{l}\text { Pipe } \\
\text { O.D. } \\
\text { (in) }\end{array}$} & \multirow{2}{*}{$\begin{array}{l}\text { Concrete } \\
\text { Thickness } \\
\text { (in) }\end{array}$} & \multirow{2}{*}{$\begin{array}{c}\text { Submerged } \\
\text { Weight } \\
\text { (lb/ft) }\end{array}$} & \multirow{2}{*}{$\begin{array}{l}\text { Soil } \\
\text { Type }\end{array}$} & \multirow{2}{*}{$\begin{array}{l}S_{\mathrm{u}} \text { or } \mathrm{D}_{\mathrm{r}} \\
\text { (psf or } \% \text { ) }\end{array}$} & \multicolumn{2}{|c|}{ Predicted embedment (in) } \\
\hline & & & & & & $\begin{array}{l}\text { Proposed } \\
\text { Method }\end{array}$ & $\begin{array}{c}\text { Dynamic } \\
\text { Simulation }\end{array}$ \\
\hline 200 & 30.00 & 4.50 & 279.4 & $\overline{\text { SAND }}$ & 10 & 6.6 & 8.2 \\
\hline 200 & 30.00 & 4.50 & 279.4 & SAND & 30 & 5.3 & 6.8 \\
\hline 200 & 30.00 & 4.50 & 279.4 & SAND & 50 & 4.3 & 5.0 \\
\hline 300 & 30.00 & 2.89 & 112.5 & SAND & 10 & 2.8 & 3.7 \\
\hline 300 & 30.00 & 2.89 & 112.5 & SAND & 30 & 2.2 & 3.0 \\
\hline 300 & 30.00 & 2.89 & 112.5 & SAND & 50 & 2.1 & 2.2 \\
\hline 200 & 30.00 & 6.25 & 476.9 & CLAY & 20 & 20.8 & 21.1 \\
\hline 200 & 30.00 & 6.25 & 476.9 & CLAY & 50 & 12.8 & 16.9 \\
\hline 200 & 30.00 & 6.25 & 476.9 & CLAY & 80 & 11.0 & 10.4 \\
\hline 300 & 30.00 & 3.68 & 192,6 & CLAY & 20 & 9.2 & 10.3 \\
\hline 300 & 30.00 & 3.68 & 192.6 & CLAY & 50 & 5.5 & 6.3 \\
\hline 300 & 30.00 & 3.68 & 192.6 & CLAY & 80 & 4.0 & 3.8 \\
\hline
\end{tabular}

Hydrodynamic Input:

$\mathrm{HS}=45 \mathrm{feet}, \mathrm{TP}=14.1 \mathrm{sec}, \mathrm{Uc}=1.0 \mathrm{ft} / \mathrm{sec}$

Table (2) Results of the Proposed Analysis - Embedment and Safety Factors

\begin{tabular}{|c|c|c|c|c|c|c|c|c|}
\hline \multirow{3}{*}{$\begin{array}{c}\text { Concrete } \\
\text { Thickness } \\
\text { (in) }\end{array}$} & \multirow{3}{*}{$\begin{array}{c}\text { Pipe } \\
\text { Weight } \\
\text { (lb/ft) }\end{array}$} & \multirow{3}{*}{$\begin{array}{l}\text { Specific } \\
\text { Gravity }\end{array}$} & \multicolumn{3}{|c|}{ Results after 4-hour build-up } & \multicolumn{3}{|c|}{ Results after additional 3-hour storm } \\
\hline & & & \multirow{2}{*}{$\begin{array}{l}\text { Embedment } \\
\text { (in) }\end{array}$} & \multicolumn{2}{|c|}{ Safety factor for } & \multirow{2}{*}{$\begin{array}{l}\text { Embedment } \\
\text { (in) }\end{array}$} & \multicolumn{2}{|c|}{ Safety factor for } \\
\hline & & & & $U(1 / 100)$ & $\mathrm{U}(1 / 1000)$ & & $\mathrm{U}(1 / 100)$ & $\mathrm{U}(1 / 1000)$ \\
\hline 2.500 & 74.2 & 1.17 & 6.4 & 0.60 & 0.51 & 6.9 & 0.69 & 0.59 \\
\hline & 86.4 & & 7 & & U. & & 0. & \\
\hline 2.75 & 98.7 & 1. & 7. & 1. & 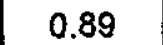 & 8. & 1. & \\
\hline & 111.0 & & 8. & 1. & & & 1. & \\
\hline 3.000 & 123.5 & 1.27 & 9. & 1.6 & & 9 & 1. & \\
\hline & 136.0 & 1.2 & 9.8 & 1.8 & 1. & 10 & 2.1 & 1.81 \\
\hline 3.250 & 148.6 & 1.2 & 10.2 & 2.1 & 1. & 1 & 2.5 & 2.13 \\
\hline 3. & 161.3 & 1.3 & 10.5 & 2.3 & 1. & 11 & 2.95 & 0 \\
\hline 3.5 & 174.1 & 1.36 & 10.8 & 2.50 & 2.11 & 12.3 & 3.42 & 2.89 \\
\hline
\end{tabular}

Pipe Parameters:

Indicates the Selected Concrete Thickness Based on the Recommended Design

Criteria

O.D. $=30^{\prime \prime}$, W.T. $=0.5^{\prime \prime}$, Concrete Density = 190 pcf, Corrosion Coating = 5/32" @ 115 pcf, Contents=none

Hydrodynamics:

Water depth $=200 \mathrm{ft}, \mathrm{HS}=45 \mathrm{ft}, \mathrm{TP}=14.1 \mathrm{sec}$, Wave Spreading $=30 \mathrm{deg}, \mathrm{UC}=1 \mathrm{ft} / \mathrm{sec}$

Soil:

Clay with remolded shear strength $=50 \mathrm{pcf}$ 


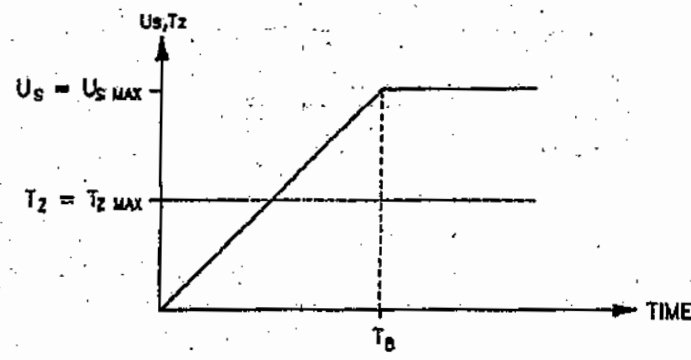

$$
\begin{aligned}
& T_{B} \text { - LENGTH OF BULDING SEA STATE (4 HOURS) } \\
& u_{s}-\text { SIGNincwt botrow velocitr }
\end{aligned}
$$

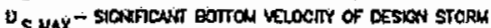

$$
\begin{aligned}
& T_{2} \text { - ZERO CROSSINO PERIOO (ON BOTTOM) } \\
& T_{Z} \text { WAX - ZERO CROSSING PERICD (ON BOTTOH) OF DESIEN STORM }
\end{aligned}
$$

Fig. 1 Assumed build-up sea state model (Hs \& Tz) used to predict pipe embedment (just prior to 3-hour design storm)

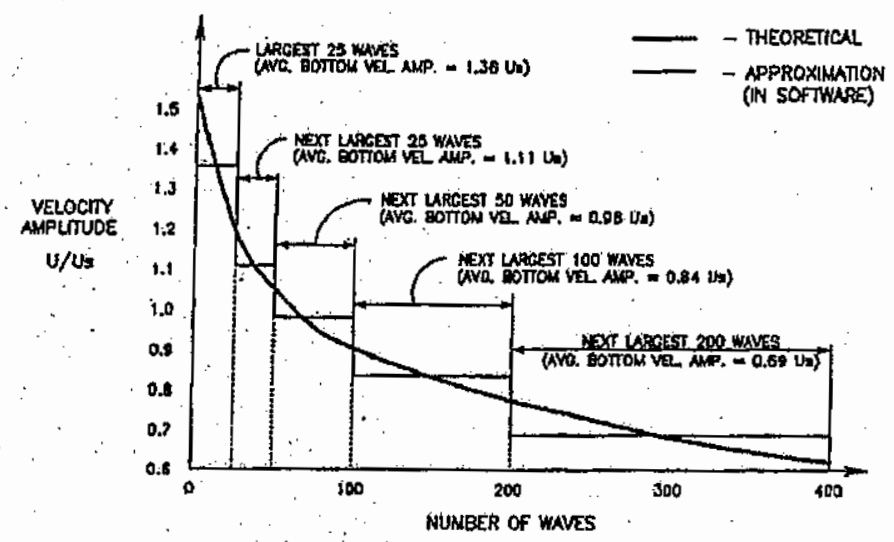

Fig. 2 Bottom Velocity Amplitude Content Of Assumed 4-Hour Storm Build-Up (Largest 400 Velocity Amplitudes Used To Predict Embedment

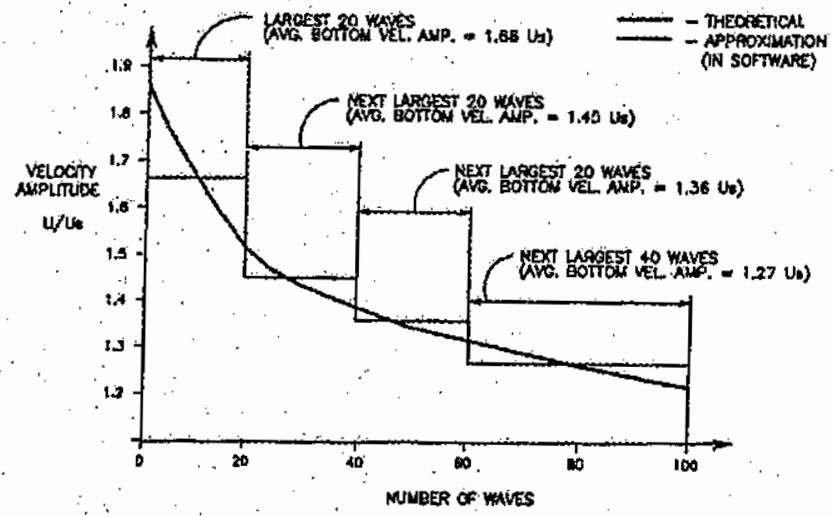

Fig. 3 Bottom velocity amplitude content of assumed 3-hour design storm (largest 100 velocity amplitudes used to predict embedment) 


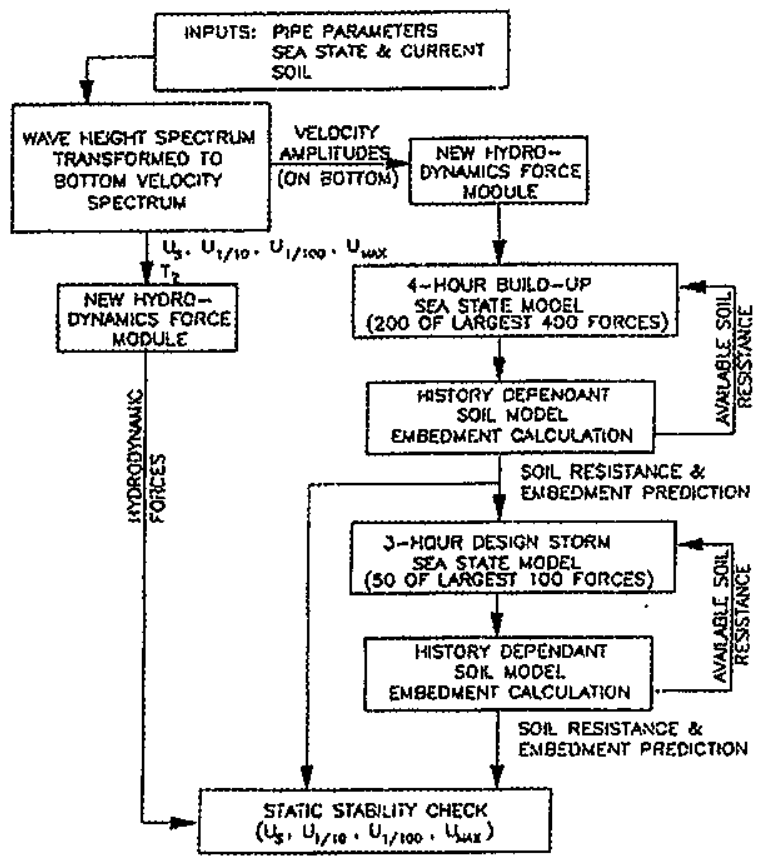

Fig. 4 Proposed design procedure

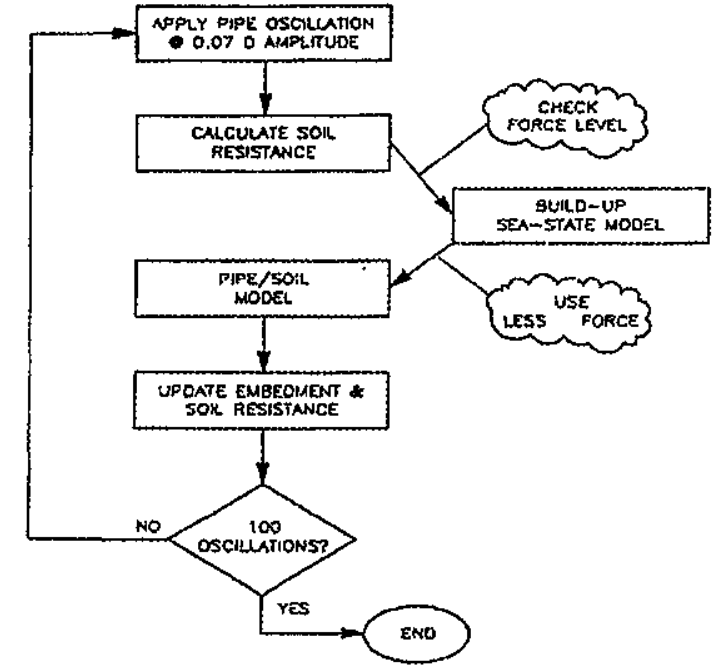

Fig. 5 Pipe embedment calculation procedure

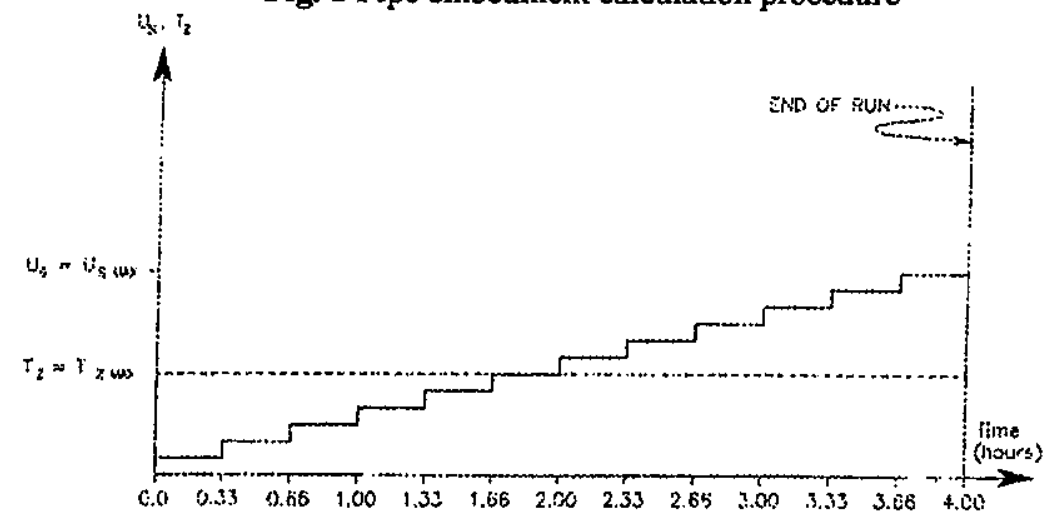

Fig. 6 Build-up sea state model used in dynamic simulations to verify/ calibrate embedment calculations 